University of Nebraska - Lincoln

DigitalCommons@University of Nebraska - Lincoln

Library Philosophy and Practice (e-journal)

Libraries at University of Nebraska-Lincoln

Winter 11-7-2021

\title{
Extending the Open Access using Extensions: Freeing Scholarly Communication from the Walled Garden
}

Subhajit Panda

Chandigarh University, Mohali, Punjab, India, suvapanda007@gmail.com

Rupak Chakravarty

Department of Library and Information Science, Panjab University, Chandigarh, India, rupak@pu.ac.in

Follow this and additional works at: https://digitalcommons.unl.edu/libphilprac

Part of the Information Literacy Commons, Scholarly Communication Commons, and the Scholarly Publishing Commons

Panda, Subhajit and Chakravarty, Rupak, "Extending the Open Access using Extensions: Freeing Scholarly Communication from the Walled Garden" (2021). Library Philosophy and Practice (e-journal). 6586.

https://digitalcommons.unl.edu/libphilprac/6586 


\title{
Extending the Open Access using Extensions: Freeing Scholarly Communication from the Walled Garden
}

\author{
Subhajit Panda ${ }^{1}$ \& Rupak Chakravarty ${ }^{2}$ \\ ${ }^{1}$ Assistant Librarian, University Library, Chandigarh University, Mohali, Punjab \\ ${ }^{1}$ Email: subhajit.e9641@ @ cumail.in \\ ${ }^{2}$ Professor, Department of Library and Information Science, Panjab University, Chandigarh \\ ${ }^{2}$ Email: rupak@pu.ac.in
}

\begin{abstract}
IFLA/FAIFE strongly advocates intellectual freedom as the basis of democracy and the core of the library concept. The spirit and philosophy of Open Access are in sync with FAIFE owing to its visible role in sharing intellectual freedom for building information democracy. The present paper is dedicated to the new and emerging technology-driven tools for researchers and academicians to access or discover OA research more easily and effectively. The main focus of the paper is to introduce to the readers about the various technology-driven tools for effective and immediate Open Access (OA) research discovery. Under this objective, mission and services of the OA discovery system CORE has been explained. Another powerful tool for OA discovery and dissemination is OA Button which comes with the collaboration of unique service tools like, InstantILL, DeliverOA, EmbedOA, OAsheet and shareyourpaper. In addition to the above two tools, this study further discusses two more stand-alone tools namely, Dataverse and Zenodo. These tools are mainly familiar with their data archiving policies. Testing the features of these tools and describing their utility and application reveal that they can help the users as well as libraries in making effective use of OA resources without any delay while also enhancing the visibility of such scholarly resources.
\end{abstract}

Keywords: Open Access, OA Tools, Plan S, cOAlition S, Creative Common Licenses, CORE, OA Button, Unpaywall, Dataverse, Zenodo

\section{Introduction:}


The real issue of implementing the new-age libraries with smart \& open access tools laid on the term "open access". Accessibility is required for every point from data discovery, access to raw data, data management, fill repositories to data sharing and archiving for future. The pricing practices and use restrictions have eroded scholarly communication by leaving libraries unable to keep pace with the increasing amount and costs of scholarly materials and prohibiting scholars from freely sharing their research. This crisis in scholarly communications creates a void between the researcher and the progress of actual research.

As per the theme of the present study of Drury's Principle (Francis Keese Wynkoop Drury, 1930) may be rewritten as "to provide the right content, to the right user, at right time". And to do so there are some initiatives (e.g. Budapest Open Access Initiatives), some licenses (e.g. Creative Common Licenses), some plans (e.g. Plan S or cOAlition S) and to implement this there are some open access tools (e.g. CORE, OA Button, Dataverse \& Zenodo), which after evaluation and comparison can be used by researcher and library professionals for discovering, utilize, dissemination and preservation of e-content, especially scholarly articles. These tools and apps can be categorized into several groups, like, tools for discovery, tools for dissemination, tools for metadata creation, tools for archiving \& preservation etc. Our present study based on such four stand-alone tools which provide almost all of these services.

\section{PLAN S/COALITION S: PRINCIPLES AND IMPLEMENTATIONS:}

cOAlition $\mathrm{S}$ is an international consortium of research funding and performing organisations who are committed to making full and immediate Open Access to research publications a reality. cOAlition $\mathrm{S}$ has developed Plan $\mathrm{S}$ whereby research funders will mandate that access to research publications that are generated through research grants that they allocate, must be free to access on the day of publication. In addition, the right to reuse the article is subject to a special type of open licence (usually the Creative Commons Attribution licence (CC-BY)) that grants the reader the right to reuse all or parts of it without having to seek additional permission, subject to appropriate attribution of the original source. Plan $S$ is a set of principles that ensure open and immediate access to funded research publications. It was first launched by cOAlition $\mathrm{S}$ in 2018. All funders who join cOAlition $\mathrm{S}$ commit to aligning their OA policies with Plan S.

The scope of Plan $S$ is primary peer reviewed research across all disciplines, including the natural and applied sciences (STEM), social sciences, and the arts and humanities. Plan S applies to all peer-reviewed publications that are based on results from research funded fully or partially by cOAlition $S$ members. The current guidance specifies the principles of Plan $S$ and provides paths for their implementation regarding scholarly articles. cOAlition $\mathrm{S}$ will, by the end of 2021, issue a statement on Plan S principles as they apply to monographs and book chapters, together with related implementation guidance. Distinctive features of this plan are enumerated below (European Science Foundation, 2021): 
i. Authors or their institutions hold the copyright of their publications and the publications must be licensed under CC-BY open license. (Attribution) in accordance with the Berlin Declaration;

ii. Quality OA Journals/Platforms/Repositories must support the Funders must create rigorous service standards and specifications;

iii. Well coordinated incentives shall be provided by the funders in cases wherein such system does not exist for its development and maintenance. Such incentives shall also include funding for establishing necessary OA infrastructure;

iv. Funders or research institutions must be covered the open access publishing fees, where applicable, not by the researchers. It is also recognized that all researchers should be able to publish their Open Access work;

v. Funders must support the various OA business models and the OA fees (with payment capping) must be transparent and justifiable through various qualitative measures standardization reflected in their services.

vi. The Funders encourage governments, universities, research organisations, libraries, academies, and learned societies to align their strategies, policies, and practices, notably to ensure transparency.

vii. The Plan-S principles shall be applicable to all types of scholarly publications, but with longer and flexible timeline in case of monographs and book chapters to attain OA AS they require separate and due process;

viii. During the transition period, the funders may financially contribute and support the 'hybrid' model of publishing through on adhoc basis.

ix. Monitoring of adherence and compliance to Plan-S principles will be undertaken by the various funding bodies and sanctions nay be levied in cases of non-compliant beneficiaries/grantees.

$\mathrm{x}$. Funding decisions will depend on the value and intrinsic merit of the work only and not on other factors including publication channel, its impact factor (or other journal metrics), or the publisher. 
"Plan S" is definitely going to have an impact on the whole OA ecosystem and implications on how the OA content is being delivered to the last man in the queue while reaching the last mile.

\section{OPEN ACCESS TOOLS:}

\section{(A) CORE}

CORE (https://core.ac.uk) its free and seamless access of millions of research papers around the world, because the main aim of core is to believe that knowledge should be used for public good and find how the knowledge can be distributed in a better way. Core collects millions of research papers from around the world and offer them free for everyone. Core has world's largest collection of OA full text which used by researchers, libraries, s/w developers, funder and many more. Our aggregated content come from thousands of institutional and subject repositories as well as journals and covers all research disciplines. It aims to support the right of citizen to access free of charge research to which they contributing by paying taxes. Provides support both content consumers and content providers by working collaboratively with them. Contribute to cultural change by promoting OA, the first growing movement for good. Make use of artificial intelligence and machine learning techniques to enrich and organize research contents support usage and discover of knowledge of their interest (CORE, 2021). CORE aggregate research papers from data providers all over the world including institutional and subject repositories and journal publishers through harvesting. It facilitates search, text mining and analytical capabilities over not only metadata, but also the full text of the research papers making CORE a unique service in the research community.It's dataset currently contains $218,769,880$ open access articles, collected from over 10,366 repositories and journals around the world.

\section{CORE Mission:}

- $\quad$ supports the right of citizens and general public to access the results of research towards which they contributed by paying taxes,

- facilitates access to open access content for all by offering services to general public, academic institutions, libraries, software developers, researchers, etc.,

- $\quad$ provides support to both content consumers and content providers by working with digital libraries, institutional and subject repositories and journals,

- enriches the research content using state-of-the-art technology and provides access to it through a set of services including search, API and analytical tools, 
- contributes to a cultural change by promoting open access, a fast-growing movement (CORE, 2021).

\section{CORE Services:}

\begin{tabular}{|c|c|c|c|c|c|}
\hline \multicolumn{6}{|c|}{ 1. Tools for Access to Raw Data } \\
\hline \multicolumn{2}{|c|}{ A. CORE API } & \multicolumn{2}{|c|}{ B. CORE Dataset } & \multicolumn{2}{|c|}{ C. CORE FastSync } \\
\hline \multicolumn{2}{|c|}{ CORE \{0에 $\longrightarrow \mathrm{Cl}_{1}$} & \multicolumn{2}{|c|}{ CORE $\because \longrightarrow C_{(D)}$} & \multicolumn{2}{|c|}{ CORE @ $\longrightarrow$ 四周 } \\
\hline \multicolumn{2}{|c|}{$\begin{array}{l}\text { Develop new applications } \\
\text { with the CORE API }\end{array}$} & \multicolumn{2}{|c|}{$\begin{array}{l}\text { Download millions of } \\
\text { research outputs for text and } \\
\text { data analysis }\end{array}$} & \multicolumn{2}{|c|}{$\begin{array}{l}\text { Keep users' data in sync with } \\
\text { CORE and never miss a new } \\
\text { research output }\end{array}$} \\
\hline & $\begin{array}{l}\text { Free real-time } \\
\text { machine access to } \\
\text { the world's largest } \\
\text { collection of open } \\
\text { access papers }\end{array}$ & 6 & $\begin{array}{l}\text { Download all } \\
\text { CORE data for big } \\
\text { data processing }\end{array}$ & (ت) & $\begin{array}{l}\text { An enterprise } \\
\text { solution to keep } \\
\text { users' data in sync } \\
\text { with research } \\
\text { content from } \\
\text { around the world }\end{array}$ \\
\hline . & $\begin{array}{l}\text { Harmonised access } \\
\text { to data from across } \\
\text { the network of } \\
\text { CORE providers }\end{array}$ & (2) & $\begin{array}{l}\text { Prototype, analyse } \\
\text { and mine users' } \\
\text { data in his/her } \\
\text { infrastructure }\end{array}$ & 氙氮 & $\begin{array}{c}\text { Spend less time } \\
\text { collecting data and } \\
\text { more on solving } \\
\text { problems }\end{array}$ \\
\hline 葛品" & $\begin{array}{l}\text { Direct machine } \\
\text { access to full texts } \\
\text { of research papers }\end{array}$ & $\stackrel{0-0}{\infty}$ & $\begin{array}{l}\text { World's largest full } \\
\text { text collection of } \\
\text { scientific papers } \\
\text { for machine } \\
\text { processing }\end{array}$ & $\equiv(0$ & $\begin{array}{c}\text { Fast and } \\
\text { incremental } \\
\text { updates as soon as } \\
\text { they become } \\
\text { available. No usage } \\
\text { restrictions }\end{array}$ \\
\hline \multicolumn{4}{|c|}{ 2. Tools for Content Discovery } & \multicolumn{2}{|c|}{$\begin{array}{l}\text { 3. Tools for Managing } \\
\text { Content }\end{array}$} \\
\hline \multicolumn{2}{|c|}{ D. CORE Recommender } & \multicolumn{2}{|c|}{ E. CORE Discovery } & \multicolumn{2}{|c|}{$\begin{array}{c}\text { F. CORE Repository } \\
\text { Dashboard }\end{array}$} \\
\hline
\end{tabular}




\begin{tabular}{|c|c|c|c|c|c|}
\hline \multicolumn{2}{|c|}{ 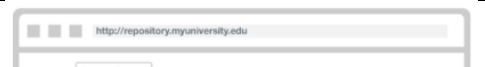 } & \multicolumn{2}{|c|}{$\because \ldots \quad \cdots \quad \cdots$} & \multicolumn{2}{|l|}{ 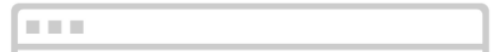 } \\
\hline \multirow{2}{*}{\multicolumn{2}{|c|}{$\overline{\bar{\equiv}}$}} & \multirow{2}{*}{\multicolumn{2}{|c|}{ 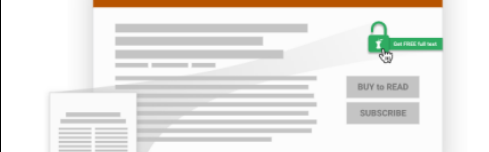 }} & \multirow{2}{*}{\multicolumn{2}{|c|}{ 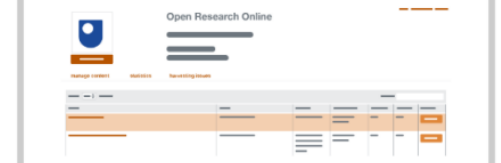 }} \\
\hline & & & & & \\
\hline \multicolumn{2}{|c|}{$\begin{array}{l}\text { A leading research papers } \\
\text { recommendation solution }\end{array}$} & \multicolumn{2}{|c|}{$\begin{array}{l}\text { One-click access to free } \\
\text { copies of research papers } \\
\text { whenever user hit the } \\
\text { paywall. CORE-Discovery } \\
\text { available as Chrome } \\
\text { extension. }\end{array}$} & \multicolumn{2}{|c|}{$\begin{array}{l}\text { Manage users' repository } \\
\text { outputs and ensure they are } \\
\text { visible to the world }\end{array}$} \\
\hline$\widetilde{0}$ & $\begin{array}{l}\text { Make repository } \\
\text { content more } \\
\text { discoverable from } \\
\text { across the global } \\
\text { network of CORE } \\
\text { data providers }\end{array}$ & 吗 & $\begin{array}{c}\text { Overcome } \\
\text { publishers' } \\
\text { paywalls by } \\
\text { discovering open } \\
\text { access versions of } \\
\text { papers }\end{array}$ & مी & $\begin{array}{c}\text { Access collection's } \\
\text { download statistics } \\
\text { and harvesting } \\
\text { status }\end{array}$ \\
\hline (Q) & $\begin{array}{l}\text { Support users in } \\
\text { finding articles } \\
\text { relevant to their } \\
\text { interests }\end{array}$ & 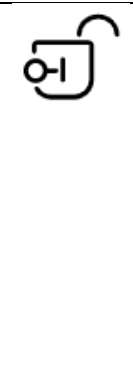 & $\begin{array}{c}\text { Backed by the } \\
\text { world's largest } \\
\text { dataset of open } \\
\text { access full texts } \\
\text { with over millions } \\
\text { of monthly active } \\
\text { users }\end{array}$ & & $\begin{array}{l}\text { Update metadata } \\
\text { records with a } \\
\text { single button click }\end{array}$ \\
\hline 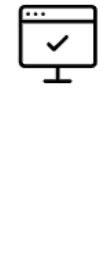 & $\begin{array}{l}\text { Easy installation to } \\
\text { all repositories, } \\
\text { journals and web } \\
\text { interfaces }\end{array}$ & & $\begin{array}{l}\text { Easy to install } \\
\text { browser extension } \\
\text { and seamless } \\
\text { repository } \\
\text { integration }\end{array}$ & Ґे & $\begin{array}{l}\text { Manage access to } \\
\text { documents from } \\
\text { users' repository in } \\
\text { CORE }\end{array}$ \\
\hline
\end{tabular}

(Sources: https://core.ac.uk/services/)

Table 1. CORE Services

\section{(B) Open Access Button:}

OA Button (OAB), launched in November 2013, envisages to facilitate such system by establishing a library-centric, open-sources, and non-commercial mechanism to avoid hitting paywalls. OA Button (now under the larger project, OA.WORKS) includes all of the world's 
aggregated repositories, hybrid articles, open access journals and those on authors' pages as the source of data, e.g. Unpaywall Data, Share, CORE, OpenAIRE, Dissem.in, Europe PMC \& BASE (Open Access Button, 2021).

\section{OA Button Tools to Deliver Articles:}

\begin{tabular}{|c|c|}
\hline Tools & Description \\
\hline Q & $\begin{array}{l}\text { - Saves Money } \\
>\text { Instantly delivers } 25 \% \text { of open accessible papers } \\
\text { - } \text { Improve Services } \\
>\text { No long forms } \\
>\text { Simple, mobile friendly interface } \\
>\text { purchase on demand, link resolver functionality/ } \\
\text { streamlined redirects, and compatible browser plugin. } \\
\text { Advances Mission } \\
>\text { Creates a cheaper ILL system } \\
>\text { Patron privacy protected } \\
\text { Easy to Install \& Maintain } \\
>\text { Easy set-up and maintenance } \\
>\text { One click pilot } \\
\text { Works with the popular systems e.g. WMS \& Serial } \\
\text { Solutions, ILLiad, Relais ILL, Tipasa, SFX and more }\end{array}$ \\
\hline (b) DeliverOA: & $\begin{array}{l}\text { DeliverOA make it easy to give the researchers Open Access } \\
\text { version of the millions of paywalled articles they need. It finds } \\
\text { self-archived Open Access versions of articles and deliver them }\end{array}$ \\
\hline
\end{tabular}




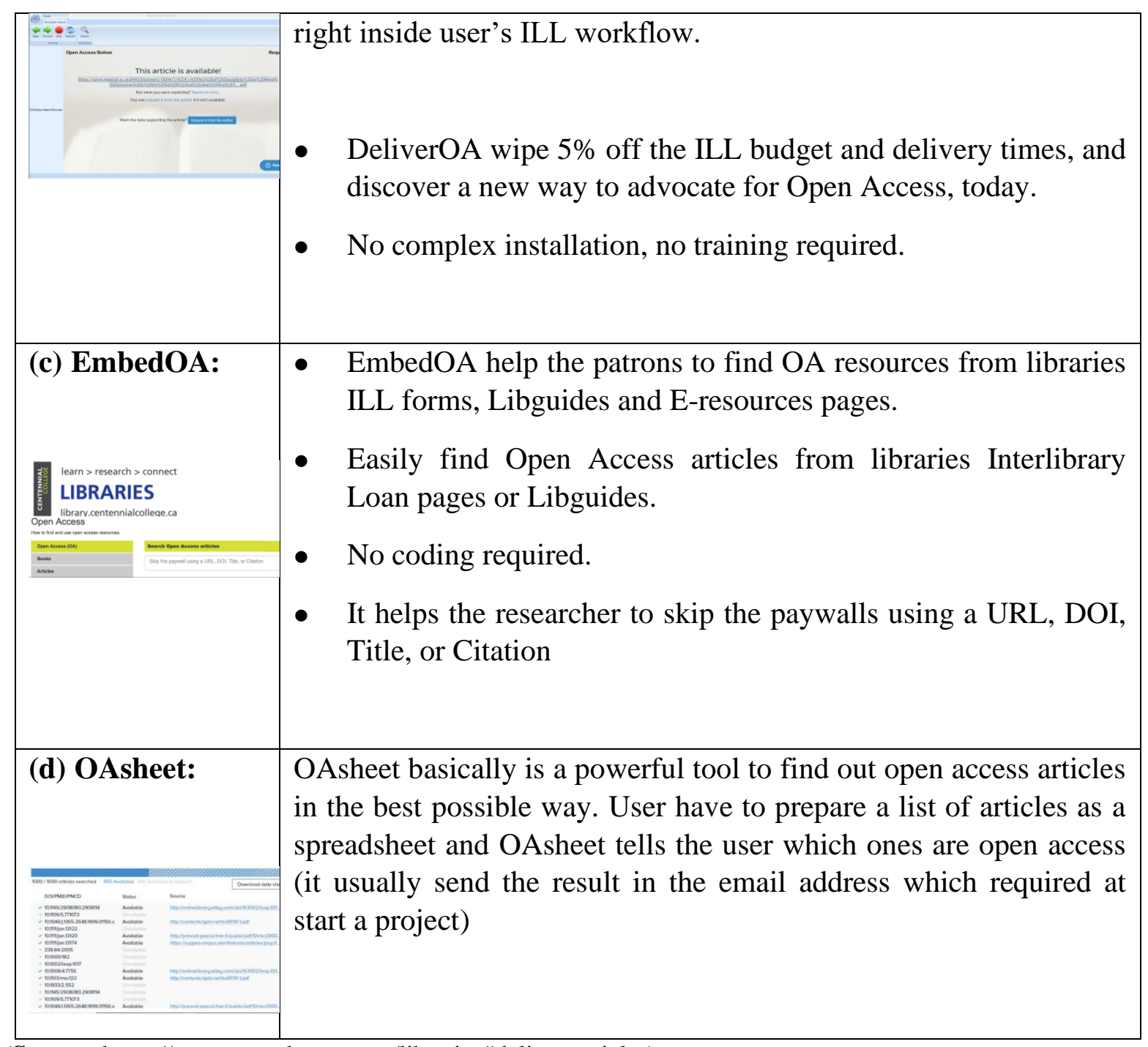

(Source: https://openaccessbutton.org/libraries\#deliver-articles)

\section{Table 2. OA Button Tools to Deliver Articles}

Open Access Button also provides some guide book for better implementation and understanding of the above-mentioned tools. Harnessing OA on the campus of the institution is a guide to overview the many ways that library and library patrons can utilize Open Access content. Here the key information about free, open-source, nonprofit, and community centric options are highlighted. Again, OA in ILL handbook is a handbook for ILL practioners on Open Access. Delivering Open Access content within ILL processes is an exciting prospect for ILL librarians with deep implications for cost, speed and ability to fill. However, it comes with new knowledge for staff to learn, and challenges to tackle. This handbook provides explainers and resources as an adjunct to tools such as DeliverOA and EmbedOA. Integration is another simple guide to integrating Open Access content into the library search \& link resolver. 


\section{OA Button Tools to Fill Repositories:}

\begin{tabular}{|c|c|}
\hline Tools & Descriptions \\
\hline (a) shareyourpaper.org & 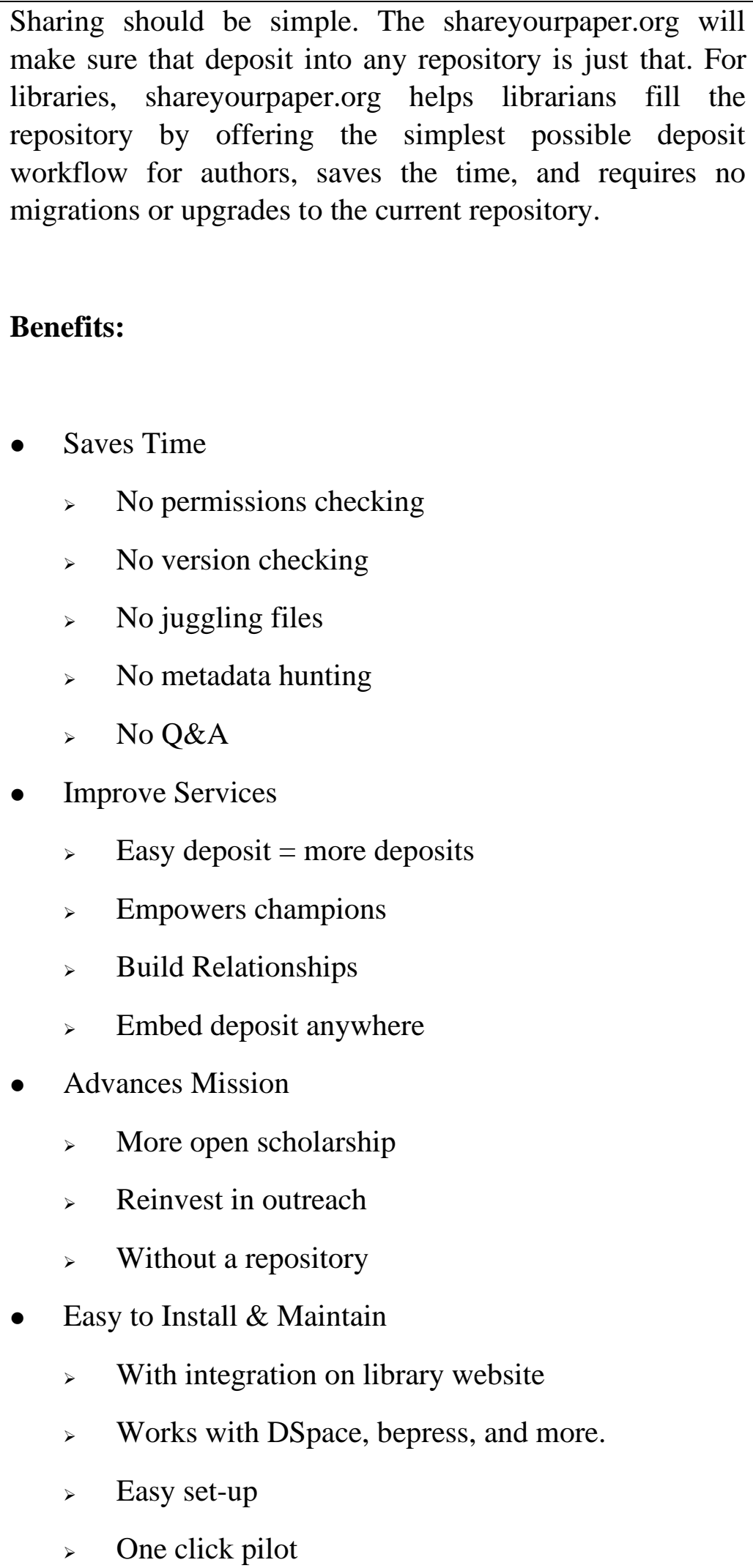 \\
\hline
\end{tabular}




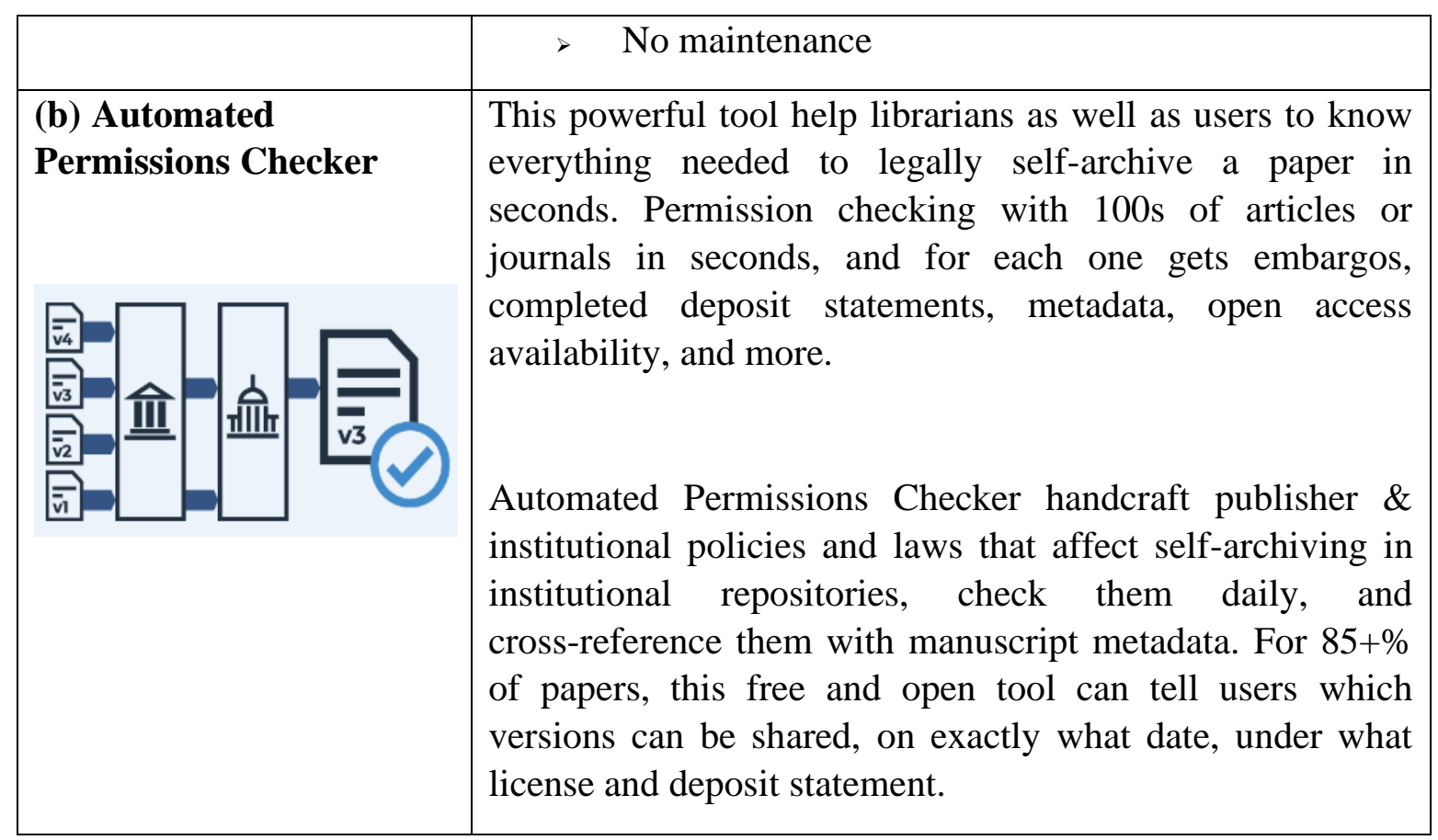

(Source: https://openaccessbutton.org/libraries\#repository)

Table 3. OA Button Tools to Fill Repositories

\section{(C) Unpaywall:}

Unpaywall is an open database of 30,471,542 free scholarly articles build by harvesting Open Access content from over 50,000 publishers and repositories, to ensure easy to discovery, track, and use. Unpaywall users read 52\% of research papers for free. This free online service is available as the Chrome/Firefox extension which is available at https://unpaywall.org/.

\section{(D) Dataverse:}

Dataverse (a virtual archive) is an open-source web application for the sharing, preservation, citation, exploration and analysis of research data. It facilitates the making of data available to others and makes it easier for the user to replicate the work of others. Researchers, journals, authors of data, publishers, distributors of data and affiliated institutions all receive visibility of academic credit and the web (Dataverse, n.d.-a). It hosts multiple virtual archives called Dataverses. Each dataverse contains datasets, and each dataset contains descriptive metadata and data files. The primary objective of Dataverse is to automate much of the job of the professional archivist, and to provide services for and to distribute credit to the data creator. Dataverse guarantees long term preservation to the, researchers. Dataverse can be placed on intitutional website giving local and customizable look, feel, branding, and URL. Dataverse Widgets can be embedded in any website to increase the visibility of scholar's datasets thus 
enabling them to achieve due recognition and full academic credit and web visibility for their scholarly work. It was developed at Harvard's Institute for Quantitative Social Science in 2006. Some of the noticeable features of Dataverse are:

- Over 80 contributors, most external to Harvard,

- 12 releases a year,

- 40 installations around the world,

- 30,000 datasets deposited in Harvard Dataverse,

- +50,000 datasets harvested from other Repositories,

- 250 new datasets added to Harvard Dataverse per month,

- 6 million downloads from Harvard Dataverse (Crosas, 2019).

\begin{tabular}{|c|c|c|c|}
\hline $\begin{array}{l}\mathbf{S} \\
\mathbf{N}\end{array}$ & \multicolumn{2}{|c|}{ Specification } & Description \\
\hline 1. & \multicolumn{2}{|c|}{ FAIR Data Principles } & Dataverse supports and endorses FAIR Data Principles \\
\hline \multirow[t]{3}{*}{2.} & \multicolumn{2}{|c|}{$\begin{array}{l}\text { Dataverse } \quad \text { Login } \\
\text { Options }\end{array}$} & \\
\hline & 2.1 & $\begin{array}{l}\text { Shibboleth Login } \\
\text { Option } \\
\text { (Institutional Log } \\
\text { In) } \\
\text { (Dataverse, 2020d) }\end{array}$ & $\begin{array}{l}\text { Shibboleth support through "single sign on" (SSO), or at } \\
\text { least "single password") } \\
\text { No need to create separate password local to the } \\
\text { Dataverse installation. }\end{array}$ \\
\hline & 2.2 & $\begin{array}{l}\text { OAuth Login } \\
\text { Options } \\
\text { (Dataverse, 2020c) }\end{array}$ & $\begin{array}{l}\text { Dataverse supports four OAuth providers: } \\
\text { - } \quad \text { ORCID, } \\
\text { - Microsoft Azure Active Directory (AD), } \\
\text { - GitHub, and } \\
\text { - Google. }\end{array}$ \\
\hline
\end{tabular}




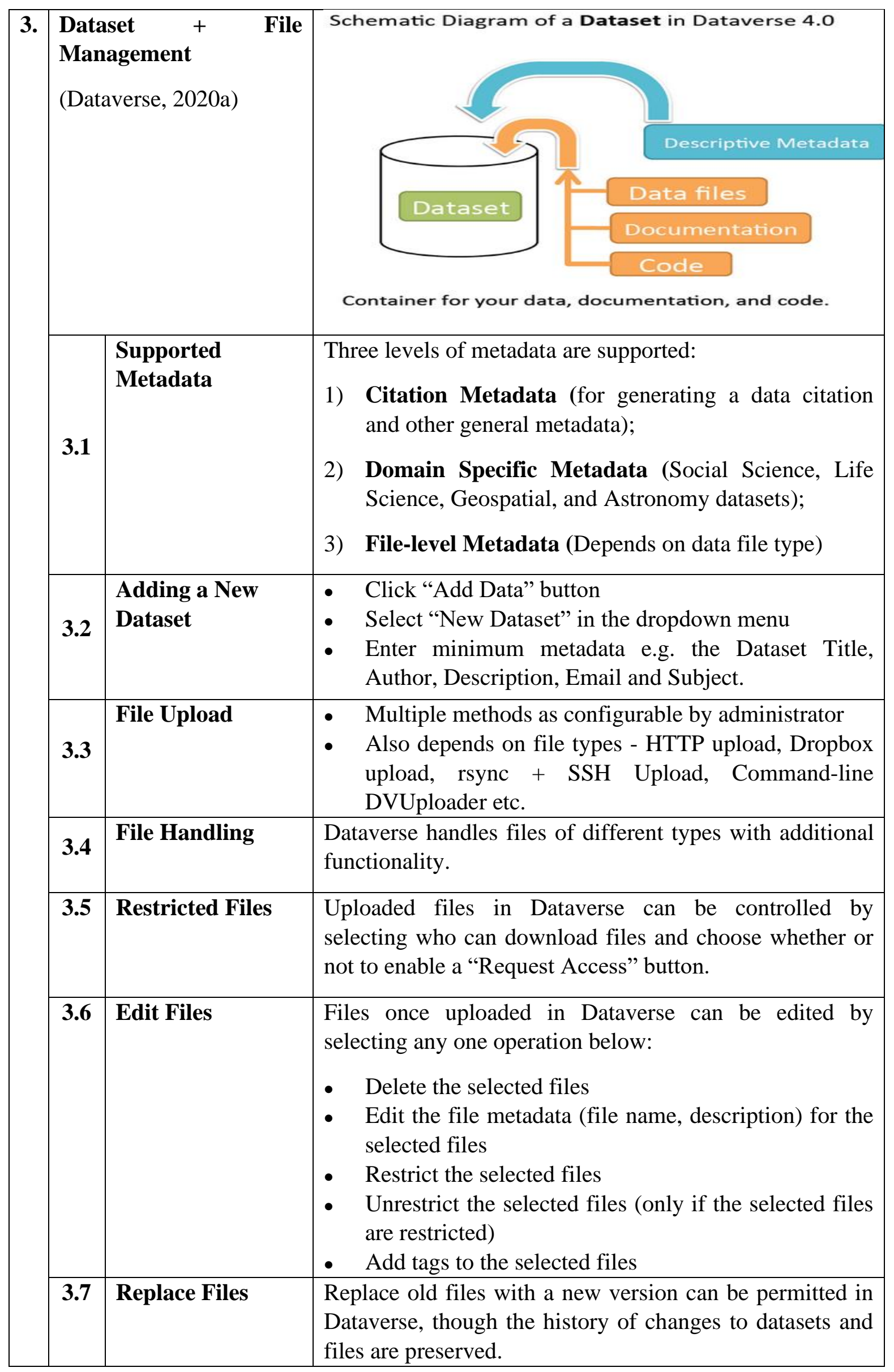




\begin{tabular}{|c|c|c|c|}
\hline \multirow[t]{4}{*}{4.} & \multicolumn{2}{|c|}{$\begin{array}{l}\text { Use Data Management } \\
\text { (Dataverse, 2020b) }\end{array}$} & \\
\hline & 4.1 & $\begin{array}{l}\text { Finding Data } \\
\text { (Faceted search) }\end{array}$ & $\begin{array}{l}\text { Log in don't mandatory for users to browse Dataverse; } \\
\text { search for dataverses, datasets and files; view published } \\
\text { datasets and subsets files and descriptions; analyze and } \\
\text { visualize data for published (restricted \& unrestricted) } \\
\text { data files. } \\
\text { Search Facilities: } \\
\text { - Basic Search } \\
\text { - Advanced Search } \\
\text { - Browsing Dataverse } \\
\text { - Saved Search } \\
\text { - File Search within Datasets }\end{array}$ \\
\hline & 4.2 & View Data & $\begin{array}{l}\text { View Dataverses + Datasets: } \\
- \text { name of the dataverse or } \\
- \text { dataset or } \\
-\quad \text { on the thumbnail image to view the dataverses, } \\
\text { datasets, and files within that dataverse; } \\
\text { View Files: through the search results or through the } \\
\text { Files table on their parent dataset's page. } \\
\text { Tree View: Files can be organized in one or more } \\
\text { folders (directories) within a dataset. } \\
\text { Switching between the traditional table view, and the } \\
\text { tree-like view showing folder and file hierarchy. }\end{array}$ \\
\hline & 4.3 & Cite Data & $\begin{array}{l}\text { Cite Data button offers the option to download the } \\
\text { citation as EndNote XML, RIS Format, or BibTeX } \\
\text { Format. }\end{array}$ \\
\hline & 4.4 & $\begin{array}{l}\text { Data Citation } \\
\text { Standard }\end{array}$ & $\begin{array}{l}\text { Dataverse standardizes the citation of datasets to make it } \\
\text { easier for researchers to publish their data and get credit } \\
\text { as well as recognition for their work. Use of universal } \\
\text { numerical fingerprints (UNFs) guarantees to the scholarly } \\
\text { community that future researchers will be able to verify } \\
\text { that data retrieved is identical to that used in a publication } \\
\text { decade earlier, even if it has changed storage media, } \\
\text { operating systems, hardware, and statistical program } \\
\text { format. }\end{array}$ \\
\hline & 4.5 & Download Data & $\begin{array}{l}\text { Individual fils can be downloaded in their original } \\
\text { formats. } \\
\text { Multiple files can be downloaded as .zip format that } \\
\text { preserves any folder structure that the dataset owner had } \\
\text { set up. }\end{array}$ \\
\hline 5. & OAI & -PMH (Harvesting) & Dublin Core, Data Document Initiative (DDI), \\
\hline
\end{tabular}




\begin{tabular}{|c|c|c|c|}
\hline & & & $\begin{array}{l}\text { OpenAIRE etc are the standardized metadata formats for } \\
\text { collect and publish metadata from and to other systems. }\end{array}$ \\
\hline 6. & \multicolumn{2}{|c|}{ Current Integrations: } & $\begin{array}{l}\text { Two Ravens (statistical tools for data exploration, } \\
\text { analysis, and meta-analysis) } \\
\text { - World Map (geospatial visualization) } \\
\text { - Open Science Framework (OSF) (open } \\
\text { collaboration during project lifecycle) } \\
\text { - Open Journal Systems (OJS) (OA Journal } \\
\text { management and publishing system. } \\
\text { - Dataverse package for R (Part of the rOpenSci } \\
\text { Project, integrates public data into the reproducible } \\
\text { research workflow } \\
\text { EZID (easy-eye-dee) (Create and manage long-term, } \\
\text { globally unique identifiers) } \\
\text { DataCite (Provides persistent identifiers (DOIs) for } \\
\text { research data) } \\
\text { SHARE ( Free, open, research data set) } \\
\text { Piwik (FOSS web analytics application that tracks } \\
\text { and analyze and reports users' online visits) } \\
\text { RSpace (electronic lab notebook (ELN) to capture } \\
\text { and organize data) }\end{array}$ \\
\hline 7. & \multicolumn{2}{|c|}{$\begin{array}{l}\text { APIs for } \\
\text { interoperability and } \\
\text { custom integrations: }\end{array}$} & $\begin{array}{l}\text { Dataverse } \\
\text { Users can click a button within Dataverse's web interface } \\
\text { to upload a file, there are many other ways to get files } \\
\text { into Dataverse, all using an API that allows for uploading } \\
\text { of files. OJS, OSF, and RSpace are all web applications } \\
\text { that can integrate with Dataverse. }\end{array}$ \\
\hline \multirow[t]{2}{*}{8.} & \multicolumn{2}{|c|}{$\begin{array}{l}\text { Dataverse Community } \\
\text { Norms: }\end{array}$} & \\
\hline & & $\begin{array}{l}\text { CC0 Waiver for } \\
\text { Datasets }\end{array}$ & $\begin{array}{l}\text { The CC0 Public Domain Dedication by default granted } \\
\text { for all the datasets ( } 4.0 \text { and on) added into Dataverse. } \\
\text { Where necessary, data depositors can opt-out from using } \\
\text { the CC } 0 \text { waiver for their datasets. }\end{array}$ \\
\hline
\end{tabular}




\begin{tabular}{|l|l|l|l|}
\hline $\mathbf{8 . 2}$ & $\begin{array}{l}\text { Crediting any } \\
\text { research used } \\
\text { with data citations }\end{array}$ & $\begin{array}{l}\text { Data that are using or referring or employing for creation } \\
\text { of new material should credit the original source with } \\
\text { proper attribution. Data that are collected from the } \\
\text { deposited datasets of Dataverse should credit the source } \\
\text { with the applicable data citation generated by Dataverse } \\
\text { under the Joint Data Citation Principles Declaration } \\
\text { (Crosas, 2013). }\end{array}$ \\
\hline $\mathbf{8 . 3}$ & $\begin{array}{l}\text { Maintaining } \\
\text { anonymity of } \\
\text { human subjects }\end{array}$ & $\begin{array}{l}\text { Strongly recommended. } \\
\text { Third Party API } \\
\text { Applications }\end{array}$ & $\begin{array}{l}\text { API applications can be designed to allow and provide } \\
\text { access to Harvard Dataverse and its materials and } \\
\text { services if they adhere to the Dataverse API Terms of Use } \\
\text { (Dataverse, n.d.-c) and Harvard Dataverse's General } \\
\text { Terms of Use (Dataverse, n.d.-d). }\end{array}$ \\
\hline
\end{tabular}

(Source 1: https://dataverse.org/integrations)

(Source 2: https://dataverse.org/best-practices/dataverse-community-norms)

Table 4. Dataverse: Policies, Features and Services

(E) Zenodo:

OpenAIRE is an acronym for "Open Access Infrastructure for Research in Europe". OpenAIRE helps Horizon 2020 researchers report their publications to the EC Participant Portal and comply with the European Commission Open Access Policy and Research Data Pilot. OpenAIRE does this by aggregating European funded research output from nearly 1000 repositories from all over the world and makes them available via the OpenAIRE portal. Zenodo (https://zenodo.org) is part of OpenAIRE. Zenodo, launched in 2013, is a multi-disciplinary open repository maintained by CERN. Datasets, documents and other research materials can be located via the Zenodo search engine. Scholars from any research discipline can upload data in any file format. A digital object identifier (DOI) is automatically assigned to all Zenodo files. The name "Zenodo" is derived from "Zenodotus", the first librarian of the Ancient Library of Alexandria and father of the first recorded use of metadata, a landmark in library history (Zenodo, 2013). All of the Zenodo Data is stored in CERN Data Center. CERN has considerable knowledge and experience in building and operating large scale digital repositories and a commitment to maintain this data centre to collect and store 100s of PBs of LHC data as it grows over the next 20 years (GRASS Wiki, 2019).

\begin{tabular}{|c|c|c|}
\hline SN & Specification & Description \\
\hline 1. & CONTENT \\
\hline
\end{tabular}




\begin{tabular}{|c|c|c|}
\hline 1.1 & Scope: & $\begin{array}{l}\text { - All Data file formats from all fields of research } \\
\text { adhering to privacy and copyright laws are acceptable. } \\
\text { Types of files include: publications (book, book } \\
\text { section, conference paper, journal article, patent, } \\
\text { preprint, report, thesis, technical note, working paper, } \\
\text { etc.), posters, presentations, datasets, images (figures, } \\
\text { plots, drawings, diagrams, photos), software, } \\
\text { videos/audio and interactive materials such as lessons. }\end{array}$ \\
\hline 1.2 & $\begin{array}{l}\text { Status of research } \\
\text { data }\end{array}$ & $\begin{array}{l}\text { Any status is accepted, from any stage of the research } \\
\text { lifecycle. }\end{array}$ \\
\hline 1.3 & Eligible depositors: & $\begin{array}{l}\text { Open repository is open to all possessing appropriate } \\
\text { submission rights. }\end{array}$ \\
\hline 1.4 & Ownership: & IPR belongs to the submitter. \\
\hline 1.5 & $\begin{array}{l}\text { Volume and size } \\
\text { limitations: }\end{array}$ & $\begin{array}{l}\text { - Total files size limit per record is 50GB. } \\
\text { - } \quad \text { Multiple dataset allowed } \\
\text { - Higher quotas can be requested and granted on a } \\
\text { case-by-case basis. }\end{array}$ \\
\hline 1.6 & $\begin{array}{l}\text { Metadata types and } \\
\text { sources: }\end{array}$ & $\begin{array}{l}\text { - Internally: JSON } \\
\text { - Metadata Export: MARCXML, Dublin Core, and } \\
\text { DataCite Metadata Schema. }\end{array}$ \\
\hline 1.7 & Language: & Preferred: English (but all languages are accepted) \\
\hline 1.8 & Licenses: & Mandatory to specify a license. \\
\hline 2. & & ACCESS AND REUSE \\
\hline 2.1 & $\begin{array}{l}\text { Access to data } \\
\text { objects: }\end{array}$ & $\begin{array}{l}\text { Files deposit -under closed/open/embargoed access. Files } \\
\text { deposited under closed access are protected against } \\
\text { unauthorized access }\end{array}$ \\
\hline 2.2 & $\begin{array}{l}\text { Restricted Access/ } \\
\text { Closed Access }\end{array}$ & $\begin{array}{l}\text { Not publicly viewable and sharing will be made possible } \\
\text { only by the approval of depositor of the original file. }\end{array}$ \\
\hline 2.3 & Embargo status: & $\begin{array}{l}\text { Allowed with restricted access till the end of the embargo } \\
\text { period, after which the content will be OA automatically. }\end{array}$ \\
\hline 2.4 & $\begin{array}{l}\text { Front page } \\
\text { accessibility }\end{array}$ & $\begin{array}{l}\text { - } \quad \text { Open Access upload displayed on the front-page } \\
\text { - } \quad \text { Closed Access upload not displayed on the front-page } \\
\text { - Embargoed Access upload displayed on the front page } \\
\text { after a certain period }\end{array}$ \\
\hline 2.5 & $\begin{array}{l}\text { Use and re-use of } \\
\text { data objects: }\end{array}$ & As per license adopted by the depositor. \\
\hline 2.6 & $\begin{array}{l}\text { Metadata access, edit } \\
\text { and reuse: }\end{array}$ & $\begin{array}{l}\text { - Metadata is licensed under } \mathrm{CC} 0 \text {, except for email } \\
\text { addresses. } \\
\text { Metadata of a published record can be easily edited } \\
\text { enabling the submitter to edit almost all of the } \\
\text { record's metadata. After editing the record should be } \\
\text { saved and published. }\end{array}$ \\
\hline
\end{tabular}




\begin{tabular}{|c|c|c|}
\hline & & $\begin{array}{l}\text { - All metadata is exported via OAI-PMH and can be } \\
\text { harvested. }\end{array}$ \\
\hline 3. & & REMOVAL \\
\hline 3.1 & Revocation: & Content not falling under Zenodo scope are removed. \\
\hline 3.2 & Withdrawal: & Upon request with valid justification, exceptional. \\
\hline 4. & & LONGEVITY \\
\hline 4.1 & Versions: & $\begin{array}{ll} & \text { New version of a record permitted } \\
\text { - } & \text { Data files are versioned. } \\
\text { - } & \text { Records are not versioned. } \\
\end{array}$ \\
\hline 4.2 & Replicas: & $\begin{array}{l}\text { - Both data files and metadata are kept in multiple } \\
\text { online and independent replicas in a distributed file } \\
\text { system, which is backed up to tape on a nightly basis. } \\
\text { - All data files are stored in CERN Data Centres, } \\
\text { primarily Geneva, with replicas in Budapest. } \\
\text { - CERN maintains this data centre to collect and store } \\
100 \text { s of PBs of LHC data as it grows over the next } 20 \\
\text { years. } \\
\text { - Closure is highly unlikely } \\
\text { - Unforeseen circumstances: Data will be migrated to } \\
\text { other suitable repositories, with perpetual discovery } \\
\text { through DOIs. }\end{array}$ \\
\hline 4.3 & Retention period: & $\begin{array}{l}\text { Lifetime retention policy at CERN Lab having } \\
\text { preservation plans for the next } 20 \text { years. }\end{array}$ \\
\hline 4.4 & $\begin{array}{l}\text { Functional } \\
\text { preservation: }\end{array}$ & Usability and understandability - not guaranteed. \\
\hline 4.5 & File preservation: & Nightly and multiple copy replication online system. \\
\hline 4.6 & $\begin{array}{l}\text { Fixity and } \\
\text { authenticity: }\end{array}$ & $\begin{array}{l}\text { Regularly check using MD5 checksum of the file content } \\
\text { integrity. }\end{array}$ \\
\hline
\end{tabular}

(Source: https://about.zenodo.org/policies/)

Table 5. Zenodo: General Policies v1.0 and Features

DOIs are freely supplied by Zenodo (prefix: 10.5281) in case the data are not having any DOI assigned prior to submission. In April 2020, Zenodo launched a Coronavirus Research Community - COVID-19 accepting data from all scientific disciplines and sub-disciplines.

\section{FAIR Data Principles and Open Access}


The Consultative Group on International Agricultural Research (CGIAR), defines Open Access as the immediate, irrevocable, unrestricted and free online access by any user worldwide to information products, and unrestricted responsible and ethical re-use of content (subject to appropriate licenses/attribution) (CGIAR, 2018). Open access can be successfully implemented if society is able to find, access and re-use the relevant content. Additionally, OA systems should promote the ability of data production, sharing, and usage systems and services to have consistent, mutual standards for the content, context, and meaning of that data (DISC, n.d.). Thus, the FAIR Data Principles resonate with the requirements of immediate open access. The FAIR Principles put specific emphasis on enhancing the ability of machines to automatically find and use the data, in addition to supporting its reuse by individuals.

\begin{tabular}{|c|c|c|}
\hline 1.1 & Findable & $\begin{array}{l}\text { F1. (meta)data are assigned a globally unique and persistent } \\
\text { identifier } \\
\text { F2. data are described with rich metadata (defined by the } \\
\text { Reusable principles below) } \\
\text { F3. metadata clearly and explicitly include the identifier of the } \\
\text { data it describes } \\
\text { F4. (meta)data are registered or indexed in a searchable } \\
\text { resource }\end{array}$ \\
\hline 1.2 & Accessible & $\begin{array}{l}\text { A1:Identifier based retrieval using open, free, and universally } \\
\text { implementable standardized communications protocol } \\
\text { allowing authentication and authorization procedure. } \\
\text { A2: Metadata are accessible, even in case of data } \\
\text { unavailability. }\end{array}$ \\
\hline 1.3 & Interoperable & $\begin{array}{l}\text { I1: Formal, accessible, shared, and broadly applicable } \\
\text { language for knowledge representation. } \\
\text { I2: Use vocabularies that follow FAIR principles } \\
\text { I3: Qualified references to other (meta)data }\end{array}$ \\
\hline 1.4 & Reusable & $\begin{array}{l}\text { R1: Richly described with a plurality of accurate and relevant } \\
\text { attributes } \\
\text { R1.1: Released with a clear and accessible data usage license } \\
\text { R1.2: Associated with detailed provenance } \\
\text { R1.3: Meet domain-relevant community standards }\end{array}$ \\
\hline
\end{tabular}

(Source: https://scholar.harvard.edu/files/mercecrosas/files/fairdata-dataverse-mercecrosas.pdf)

Table 6. The FAIR Guiding Principles

\section{CONCLUSIONS AND RECOMMENDATIONS:}


FAIFE (Freedom of Access to Information and Freedom of Expression) is an initiative within IFLA to defend and promote the basic human rights defined in Article 19 of the United Nations Universal Declaration of Human Rights. IFLA/FAIFE aims to raise awareness of the essential correlation between the library concept and the values of intellectual freedom (IFLA, 2018). The focal point of this initiative lies in freedom of access to information and freedom of expression in all aspects, directly or indirectly, related to libraries and librarianship through collaborative efforts. IFLA/FAIFE firmly believes and strongly endorses the intellectual freedom is the right of every individual to both hold and express opinions and to seek and receive information. Zenedo is the living example of information democracy is the OpenAIRE's trusted open repository hosted by CERN. It enables researchers from all disciplines to share and preserve their research outputs, regardless of size or format (OpenAIRE, 2018). According to "cOAlition S, "open access is foundational to the scientific enterprise". Universality is a fundamental principle of knowledge and it can lead to growth and development only if research results are made openly available to the community for validation and productive use without the need to reinventing the wheel. Besides, new research builds on preceding research results. The chain, through which new scientific discoveries are built on previously developed findings, will only work optimally if all research results are made available freely to the scientific community. Publication paywalls hide a vast amount of research findings from a significant segment of society that hampers its access and use (Schiltz, 2018). In the 21st century, the paywalls must be terminated in order to provide service to help researchers disseminate their results. Open Access is for the welfare of the humanity and organizations, associations, governments and libraries should take every step to to strengthen through effective and sustainable measures.

\section{REFERENCE:}

CORE. (n.d.-a). About CORE. Retrieved October 16, 2021, from https://core.ac.uk/about/

CORE. (n.d.-b). About CORE | Mission. Retrieved October 16, 2021, from https://core.ac.uk/about/\#mission

CORE. (n.d.-c). CORE Services. Retrieved June 8, 2020, from https://core.ac.uk/services/

CORE. (n.d.-d). Data providers. Retrieved October 16, 2021, from https://core.ac.uk/data/providers/

CGIAR. (2018, November 28). Open Access and Fair Principles. Retrieved October 13, 2021, from https://ccafs.cgiar.org/open-access-and-fair-principles\#.XuZ5pGgzbIV 
Crosas, M. (2019). The FAIR Guiding Principles: Implementation in Dataverse. Retrieved from https://scholar.harvard.edu/files/mercecrosas/files/fairdata-dataverse-mercecrosas.pdf

Dataverse. (n.d.-a). Harvard Dataverse API Terms of Use. Retrieved October 10, 2021, from https://dataverse.org/best-practices/harvard-api-tou

Dataverse. (n.d.-b). Harvard Dataverse General Terms of Use. Retrieved October 10, 2021, from https://dataverse.org/best-practices/harvard-dataverse-general-terms-use

DISC. (n.d.). What is "Data Interoperability?" Retrieved October 13, 2021, from The Data Interoperability Standards Consortium website: https://datainteroperability.org/

European Science Foundation. (2021). "Plan S" and "cOAlition S" - Accelerating the transition to full and immediate Open Access to scientific publications. Retrieved October 23, 2021, from https://www.coalition-s.org/

GRASS Wiki. (2019, May 19). GitHub-Zenodo linkage. Retrieved October 11, 2021, from grasswiki.osgeo.org website: https://grasswiki.osgeo.org/wiki/GitHub-Zenodo_linkage

IFLA. (2018, November 20). IFLA -- Freedom of Access to Information and Freedom of Expression (FAIFE) Advisory Committee. Retrieved October 14, 2021, from https://www.ifla.org/faife

Open Access Button. (n.d.-a). Open Access Button. Retrieved October 18, 2021, from https://openaccessbutton.org/about

Open Access Button. (n.d.-b). Powerfully Simple Tools to Deliver Articles. Retrieved June 8, 2020, from https://openaccessbutton.org/libraries\#deliver-articles

Open Access Button. (n.d.-c). Powerfully Simple Tools to Fill Repositories. Retrieved June 8, 2020, from https://openaccessbutton.org/libraries\#repository

OpenAIRE. (2018, May 6). Zenodo | What it is. Retrieved October 14, 2021, from https://www.openaire.eu/zenodo/ 
Schiltz, M. (2018, September 4). Why Plan S | Plan S. Retrieved October 14, 2021, from Coalition-s.org website: https://www.coalition-s.org/why-plan-s/

Zenodo. (2013, May). About Zenodo. Retrieved October 11, 2021, from Zenodo.org website: https://about.zenodo.org/

Zenodo. (n.d.). General Policies v1.0. Retrieved October 11, 2021, from https://about.zenodo.org/policies/ 